Sādhanā Vol. 40, Part 7, October 2015, pp. 2021-2043. (C) Indian Academy of Sciences

\title{
An improved methodology for dynamic modelling and simulation of electromechanically coupled drive systems: An experimental validation
}

\author{
NUH ERDOGAN $^{1, *}$, HUMBERTO HENAO ${ }^{2}$ and \\ RICHARD GRISEL ${ }^{3}$
}

\author{
${ }^{1}$ Department of Electrical and Electronics Engineering, Atilim University, \\ 06836 Ankara, Turkey \\ ${ }^{2}$ Department of Electrical Engineering, University of Picardie J.V., 80000 \\ Amiens, France \\ ${ }^{3}$ IUT-LEMI, University of Rouen, 76821 Mont Saint Aignan Cedex, France \\ e-mail: nuh.erdogan@atilim.edu.tr
}

MS received 22 July 2014; revised 27 May 2015; accepted 20 June 2015

\begin{abstract}
The complexity of electromechanical coupling drive system (ECDS)s, specifically electrical drive systems, makes studying them in their entirety challenging since they consist of elements of diverse nature, i.e. electric, electronics and mechanics. This presents a real struggle to the engineers who want to design and implement such systems with high performance, efficiency and reliability. For this purpose, engineers need a tool capable of modelling and/or simulating components of diverse nature within the ECDS. However, a majority of the available tools are limited in their capacity to describe the characteristics of such components sufficiently. To overcome this difficulty, this paper first proposes an improved methodology of modelling and simulation for ECDS. The approach is based on using domain-based simulators individually, namely electric and mechanic part simulators and also integrating them with a co-simulation. As for the modelling of the drive machine, a finely tuned dynamic model is developed by taking the saturation effect into account. In order to validate the developed model as well as the proposed methodology, an industrial ECDS is tested experimentally. Later, both the experimental and simulation results are compared to prove the accuracy of the developed model and the relevance of the proposed methodology.
\end{abstract}

Keywords. Electromechanical coupling; electric drive system; co-simulation; dynamic modelling; induction machine; saturation; domain-based simulators.

*For correspondence 


\section{Introduction}

Studying electromechanical coupling drive system (ECDS) is a complicated task, since they are composed of components of different natures such as power converter, electrical machines, somehow sophisticated control circuits, kinematics chain and mechanical load (Kern \& Hunz 1993; Doumbia 1997; Lechevalier et al 1999). The diversity of the processes and the complexity of the drive system itself present a real challenge to engineers who intend to design and implement such systems with high performance, efficiency and reliability (Doumbia 1997; Gole et al 1997; Wurtz et al 1998). As such, prior to putting ECDS into practice, modelling and simulation of the system plays a prominent role.

The first step of a model simulation is the choice of appropriate simulation tools (Larsson et al 2001). Unfortunately, the majority of available simulation tools are restricted to describing only the characteristics of the different parts of an ECDS in detail. Besides, the programs do not have the ability to integrate electrical and mechanical simulation tools for ECDS. To overcome this difficulty, a modular method approach is proposed in the literature which consists of dividing the system into several functional blocks/modules (Kern \& Hunz 1993; Lechevalier et al 1999). Several studies have proposed the realization of ECDS by using dynamic simulation environments such as Matlab ${ }^{\circledR} /$ SIMULINK (Gerbaud et al 1992; Capolino \& Henao 1990; Henao et al 1997; Doumbia 1997). This approach is based on electrical equivalents of mechanical parts. Here, the main problem is to utilize similar types of simulation tools adapted for diverse-natured systems, i.e. electrical and mechanical parts. To integrate such systems in a feasible way, one should take the necessary steps to find a solution to bring about interaction between the tools. Consequently, thoroughly analysing multi-domain systems, such as ECDSs have long been a difficult task for engineers.

The present study is concerned with dynamic modelling and simulation of industrial systems where the configuration is composed of an electrical machine-converter-kinematics chain and a mechanical load. The objective is to develop a new approach to dynamic modelling and/or simulation of an ECDS from the point of view of electrical engineering. In the system where the machine accelerates under high-inertia loads, it is frequent to encounter certain problems at the starting phase. The inrush currents produce torques oscillations and, in some cases, these oscillations resonate with the mechanical load, resulting in a premature failure of couplings/geartrains (Lipo \& Consoli 1984; Fuchs et al 1988). Therefore, a dynamic drive machine model is required when modelling an ECDS. This paper first begins by introducing a methodology for modelling and simulation of ECDSs based on a potential co-simulation that integrates two simulation tools, each of which is in turn adapted for its respective diverse system component. Secondly, taking into account the magnetic saturation, a drive machine dynamic model is proposed. The model of the electrical part is implemented in Matlab ${ }^{\circledR / S I M U L I N K}$, and the model for the mechanical part in ITI ${ }^{\circledR}$-SIM, which is a highly intuitive simulation tool based on object-oriented language for the dynamic simulation of mechanical systems (ITI ${ }^{\circledR}$. SIM 1999). To simulate entire ECDSs, a co-simulation is performed by launching the model in Matlab ${ }^{\circledR} /$ SIMULINK to automatically drive the mechanical model. Finally, an experimental study is carried out using an industrial ECDS test bed. The simulated and experimental results are gathered and found to be in satisfactory correlation. In the end, these results are compared to prove the accuracy of the developed model and the relevance of the proposed methodology. 


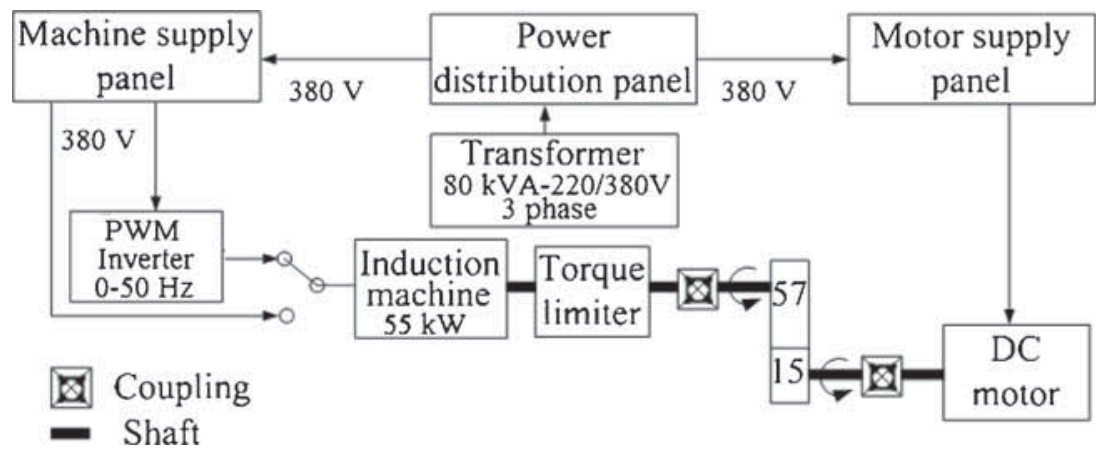

Figure 1. Schematic representation of the examined industrial ECDS.

\section{System description}

A typical industrial ECDS consists of an electric part associated with electrical machines and their supplies, as well as a mechanical part associated with a kinematics chain/mechanical load linked together. The machines are supplied either through a power converter or directly from the network. In this study, an industrial ECDS setting has been tested experimentally. As shown in figure 1, a three-phase $55 \mathrm{~kW}$-induction motor drives a ring gear box through a torque limiter. The goal of using the torque limiter is to avoid high starting torque peaks, by adjusting the limiter to maximum 1.5 times the rated torque value. The ring gear box consists of 57 and 15 teeth, respectively, which means a gear ratio of 3.8. The braking of the gear box is assured by a DC motor. On the shaft system, two couplings are used. The first coupling is located between the drive motor and the gear box, whereas the second one is placed between the gear box and the DC motor.

\section{Proposed methodology}

The modelling of an ECDS involves the modelling of its electrical and the mechanical parts, which use their own graphic user interface (Johansson et al 2000; Larsson et al 2001, 2002). Therefore, it is essential to integrate these tools in order to simulate the behaviour of the entire system. One way of integrating the tools is to use a co-simulation environment as an interface between the simulation tools for electrical and mechanical parts (Larsson et al 2001; Koo 2004). At this stage, it is important to choose the proper simulation tools for each part. Although specialized tools such as EMTP, PSpice, Modelica, VHDL, ITI ${ }^{\circledR}$-SIM, ADAMS are effective in modelling the specific event, general simulation tools such as Matlab ${ }^{\circledR}$ provide the user with tools for creating user-defined models (Capolino \& Henao 1990; Kern \& Hunz 1993; Gole et al 1997; Henao et al 1997; Doumbia 1997; Johansson et al 2000; Larsson et al 2001, 2002; Schoder \& Feliachi 2004; Faruque et al 2006; Gamino et al 2006). If there is a multi-domain system, it is reasonable to use specific simulation tools for each domain. The proposed methodology is based on using domain-based simulators individually, namely electric and mechanic part simulators, and also on integrating these with a co-simulation. The ECDS is modelled with the state variable method (Champagne et al 2004). Certain tools from Matlab ${ }^{\circledR} /$ SIMULINK are used to implement and simulate the electric parts of the ECDS. The Matlab ${ }^{\circledR} /$ SIMULINK can be interfaced by means of co-simulation with the ITI ${ }^{\circledR}$-SIM simulator, which is selected for the mechanical 


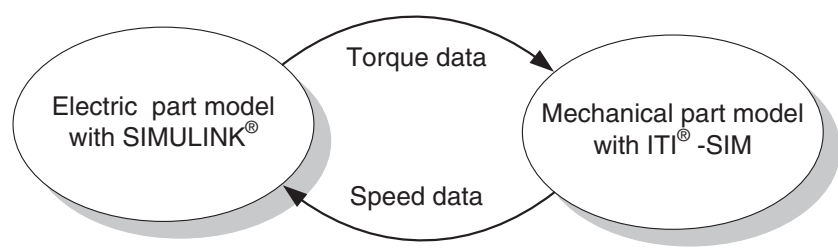

Figure 2. The structure of the Co-simulation between two different simulation tools.

part simulation purposes (SIMULINK ${ }^{\circledR}$ 2001). The ITI ${ }^{\circledR}$-SIM simulation software package is used for modelling, analyzing, and optimizing dynamically stressed, complex nonlinear systems (ITI ${ }^{\circledR}$-SIM 1999). These simulation model structures are defined interactively using a graphic user interface. Also, the model elements are selected from physically oriented application libraries containing ready-made macro models of mechanical elements.

Co-simulation: The simulation of the overall ECDS can be accomplished by two methods (Larsson et al 2001). In the first method, the models are exported to the simulation environment, which uses a powerful numerical solver. In the second method, the models are kept in their original environments and bi-directional data transfer is performed by a co-simulation as shown in figure 2. In this study, the latter method is applied. The interface between the tools is made by an S-function in SIMULINK ${ }^{\circledR}$. This function is a type of DLL and is provided by ITI ${ }^{\circledR}$-SIM. The S-function requires four parameters: the ITI ${ }^{\circledR}$-SIM model name, the communication step width, the number of inputs corresponding to the number of outputs in the ITI ${ }^{\circledR}$-SIM model, and the number of outputs corresponding to the number of inputs in the ITI ${ }^{\circledR}$-SIM model. The parameters of the S-function specify the communication link to the ITI ${ }^{\circledR}$-SIM model. On the ITI ${ }^{\circledR}$-SIM side, appropriate sender and receiver blocks complete the coupling.

\section{Modelling of the electrical part}

\subsection{Induction machine drive model}

Conventionally, the prediction of induction machine performance has always been based on constant parameter models yielding satisfactory results for both steady-state and some transient conditions. However, these conventional models have not been accurate sufficiently for certain large-signal transient conditions such as line starting, braking, operating with faults in supply, and supply with PWM converters (Smith et al 1996; Li \& Xu 2001). As a result, the need for an accurate machine model that takes into account the variations on the machine parameters becomes imperative (Lipo \& Consoli 1984; Fuchs et al 1988; Boldea \& Nasar 1988).

In this study, a two-phase axis machine model is used in which the parameters' variations are adapted according to non-linear phenomena. The voltage equations of a three-phase squirrel cage induction machine in $\mathrm{q}-\mathrm{d}$ axes are expressed in a matrix form by

$$
\left[\begin{array}{c}
v_{q s} \\
v_{d s} \\
0 \\
0
\end{array}\right]=\left[\begin{array}{cccc}
R_{s} & 0 & 0 & 0 \\
0 & R_{s} & 0 & 0 \\
0 & 0 & R_{s} & 0 \\
0 & 0 & 0 & R_{s}
\end{array}\right]\left[\begin{array}{c}
i_{q s} \\
i_{d s} \\
i_{q r}^{\prime} \\
i_{d r}^{\prime}
\end{array}\right]+\frac{d}{d t}\left[\begin{array}{c}
\lambda_{q s} \\
\lambda_{d s} \\
\lambda_{q r}^{\prime} \\
\lambda_{d r}^{\prime r}
\end{array}\right]+\left[\begin{array}{cccc}
0 & \omega & 0 & 0 \\
-\omega & 0 & 0 & 0 \\
0 & 0 & 0 & \left(\omega-\omega_{r}\right) \\
0 & 0 & -\left(\omega-\omega_{r}\right) & 0
\end{array}\right]\left[\begin{array}{c}
\lambda_{q s} \\
\lambda_{d s} \\
\lambda_{q r}^{\prime} \\
\lambda_{d r}^{\prime}
\end{array}\right]
$$


Note that all the rotor variables are referred to the stator side. The flux linkages $\lambda_{q s}, \lambda_{d s}, \lambda_{q r}^{\prime}, \lambda_{d r}^{\prime}$ consist of leakage and magnetizing flux linkages and can be written by the following equation:

$$
\begin{aligned}
& \lambda_{q s}=\lambda_{q l s}+\lambda_{q m} . \\
& \lambda_{d s}=\lambda_{d l s}+\lambda_{d m} . \\
& \lambda_{q r}^{\prime}=\lambda_{q l r}^{\prime}+\lambda_{q m} . \\
& \lambda_{d r}^{\prime}=\lambda_{d l r}^{\prime}+\lambda_{d m} .
\end{aligned}
$$

The leakage and magnetizing inductances are functions of exciting currents. The time derivatives of the flux linkages can be calculated as follows:

$$
\begin{aligned}
& \frac{d \lambda_{q s}}{d t}=\frac{d \lambda_{q l s}}{d i_{q s}} \cdot \frac{d i_{q s}}{d t}+\frac{d \lambda_{q m}}{d t} . \\
& \frac{d \lambda_{d s}}{d t}=\frac{d \lambda_{d l s}}{d i_{d s}} \cdot \frac{d i_{d s}}{d t}+\frac{d \lambda_{d m}}{d t} . \\
& \frac{d \lambda_{q r}^{\prime}}{d t}=\frac{d \lambda_{q l r}^{\prime}}{d i_{q r}^{\prime}} \cdot \frac{d_{q r}^{\prime}}{d t}+\frac{d \lambda_{q m}}{d t} . \\
& \frac{d \lambda_{d r}^{\prime}}{d t}=\frac{d \lambda_{d l r}^{\prime}}{d i_{d r}^{\prime}} \cdot \frac{d i_{d r}^{\prime}}{d t}+\frac{d \lambda_{d m}}{d t} .
\end{aligned}
$$

\subsection{Magnetizing flux saturation}

Initially, the magnetizing flux saturation within the saturated flux linkages expressed in Eq. (2) is handled. We consider a two-axis equivalent model of the machine as presented in figure 3 . It is assumed that there is a unique magnetizing flux linkage along each of the orthogonal axes as $\lambda_{q m}, \lambda_{d m}$ resulting from the magnetizing current $\mathrm{i}_{\mathrm{m}}$ (Boldea \& Nasar 1988; Levi 1997; Li \& $\mathrm{Xu}$ 2001). Each flux interacts with the other, thus creating cross-coupling between the axes. It is

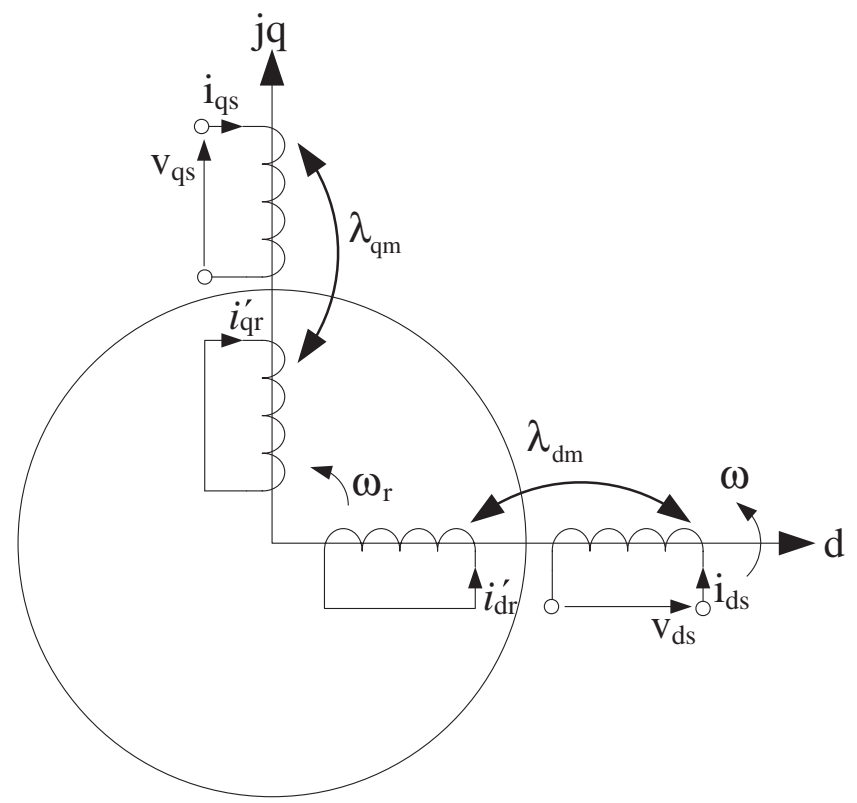

Figure 3. Two-axis equivalent model of the induction machine representing magnetizing flux linkages on the quadrature axes. 
assumed that this cross-coupling is saturated. The magnetizing current is given by the following equation:

$$
i_{\mathrm{m}}=\sqrt{i_{\mathrm{qm}}^{2}+i_{\mathrm{dm}}^{2}}
$$

where $i_{\mathrm{qm}}=i_{q s}+i_{q r}^{\prime}$, and $i_{\mathrm{dm}}=i_{d s}+i_{d r}^{\prime}$.

According to Boldea \& Nasar (1988), the associated inductances on the quadrature axes are defined as follows:

$$
\begin{aligned}
& L_{\mathrm{qm}}\left(i_{\mathrm{m}}\right)=\frac{\lambda_{\mathrm{qm}}^{*}\left(i_{\mathrm{m}}\right)}{i_{\mathrm{m}}} . \\
& L_{\mathrm{dm}}\left(i_{\mathrm{m}}\right)=\frac{\lambda_{\mathrm{dm}}^{*}\left(i_{\mathrm{m}}\right)}{i_{\mathrm{m}}} .
\end{aligned}
$$

where $\lambda_{\mathrm{qm}}^{*}$ and $\lambda_{\mathrm{dm}}^{*}$ are the q-axis and d-axis saturated magnetizing flux linkages respectively as functions of the magnetizing current. Then magnetizing flux expressions in Eq. (2) become as follows:

$$
\begin{aligned}
& \lambda_{\mathrm{qm}}=\frac{\lambda_{\mathrm{qm}}^{*}\left(i_{\mathrm{m}}\right)}{i_{\mathrm{m}}} \cdot i_{\mathrm{qm}} . \\
& \lambda_{\mathrm{dm}}=\frac{\lambda_{\mathrm{dm}}^{*}\left(i_{\mathrm{m}}\right)}{i_{\mathrm{m}}} \cdot i_{\mathrm{dm}} .
\end{aligned}
$$

Thus, the time derivatives of the magnetizing flux are given by the following equation (Boldea \& Nasar 1988),

$$
\begin{aligned}
& \frac{d \lambda_{\mathrm{qm}}}{d \mathrm{t}}=L_{\mathrm{q}-\mathrm{qm}} \cdot \frac{d i_{\mathrm{qm}}}{d \mathrm{t}}+L_{\mathrm{q}-d \mathrm{~m}} \cdot \frac{d i_{d \mathrm{~m}}}{d \mathrm{t}} . \\
& \frac{d \lambda_{d \mathrm{~m}}}{d \mathrm{t}}=L_{d-d \mathrm{~m}} \cdot \frac{d i_{d \mathrm{~m}}}{d \mathrm{t}}+L_{d-\mathrm{qm}} \cdot \frac{d i_{\mathrm{qm}}}{d \mathrm{t}} .
\end{aligned}
$$

With $L_{\mathrm{q}-\mathrm{qm}}=l_{m} \cdot \frac{i_{\mathrm{qm}}^{2}}{i_{\mathrm{m}}^{2}}+L_{\mathrm{m}} \cdot \frac{i_{d \mathrm{~m}}^{2}}{i_{\mathrm{m}}^{2}} ; L_{d-d \mathrm{~m}}=l_{m} \cdot \frac{i_{d \mathrm{~m}}^{2}}{i_{\mathrm{m}}^{2}}+L_{\mathrm{m}} \cdot \frac{i_{\mathrm{qm}}^{2}}{i_{\mathrm{m}}^{2}} ; L_{\mathrm{q}-\mathrm{dm}}=L_{d-\mathrm{qm}}=\left(l_{m}-L_{\mathrm{m}}\right) \cdot \frac{i_{\mathrm{qm}} \cdot i_{d \mathrm{~m}}}{i_{\mathrm{m}}^{2}}$. whereas $L_{\mathrm{q}-\mathrm{qm}}$ and $L_{d-\mathrm{dm}}$ represent the magnetizing inductances on the q-axis and d-axis, respectively. $L_{\mathrm{q}-\mathrm{dm}}$ and $L_{d-\mathrm{qm}}$ represent the cross-coupling between the q-d axes. The terms $l_{m}$, and $\mathrm{L}_{\mathrm{m}}$ in the inductance expressions are given by the following equation:

$$
\begin{aligned}
& l_{m}=\frac{d \lambda_{m}}{d i_{m}} . \\
& L_{m}=\frac{\lambda_{m}}{i_{m}} .
\end{aligned}
$$

$l_{m}$, and $L_{\mathrm{m}}$ describe the dynamic and steady-state magnetizing inductances, respectively. The magnetizing curve is required to determine the inductances expressed in Eq. (8). This curve can be obtained by no-load tests for a range of supply voltage values from 0.4 pu to $1.3 \mathrm{pu}$. Supposing that the slip is almost zero $\left(I_{m} \cong I_{0}\right)$ and that the voltage drop on the stator leakage reactance is negligible for no-load operations, we can write the following relation:

$$
\lambda_{\mathrm{m}}=\frac{\mathrm{V}_{\mathrm{s}}-\mathrm{R}_{\mathrm{s}} \cdot \mathrm{I}_{0}}{\omega_{\mathrm{e}}} .
$$

Using Eq. (9), the magnetizing flux is calculated for different magnetizing current values. This curve has been obtained as shown in figure 4 . The measured values can be represented by a 


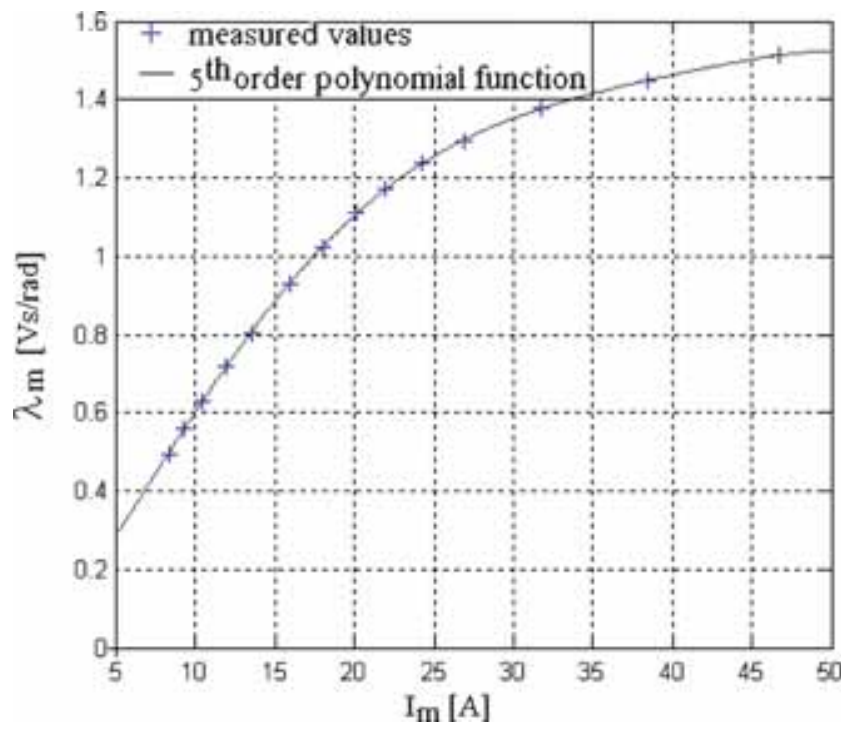

Figure 4. Magnetizing curve of tested three-phase induction machine.

$5^{\text {th }}$-order polynomial function, which enables us to calculate the inductances defined in Eq. (8). The calculated inductances are shown in figure 5.

\subsection{Leakage flux saturation}

The first terms of flux derivatives in Eq. (3) express the leakage inductances as follows:

$$
l_{l s}=\frac{d \lambda_{q l s}}{d i_{q s}}=\frac{d \lambda_{d l s}}{d i_{d s}} .
$$

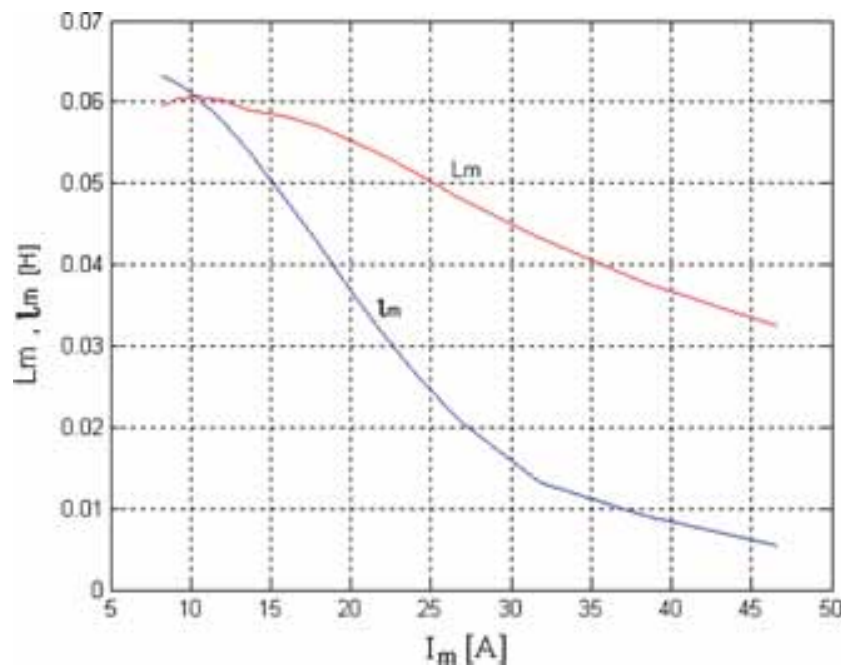

Figure 5. Variations of calculated magnetizing inductances versus magnetizing current. 


$$
l_{l r}^{\prime}=\frac{d \lambda_{q l r}^{\prime}}{d i_{q r}^{\prime}}=\frac{d \lambda_{d l r}^{\prime}}{d i_{d r}^{\prime}} .
$$

These parameters can be obtained by rotor blocked tests at unit slip. For blocked rotor operations, supposing that $\mathrm{I}_{\mathrm{s}} \cong \mathrm{I}_{\mathrm{r}}^{\prime}$ and $\lambda_{\mathrm{ls}}=\lambda_{\mathrm{lr}}^{\prime}$, the stator leakage flux can be calculated as given by the following equation:

$$
\lambda_{\mathrm{ls}}=\frac{\mathrm{V}_{\mathrm{s}}-\left(\mathrm{R}_{\mathrm{s}}+\mathrm{R}_{\mathrm{r}}^{\prime}\right) \cdot \mathrm{I}_{\mathrm{s}}}{2 \cdot \omega_{\mathrm{e}}} .
$$

Using Eq. (12), the stator leakage flux is calculated for different stator current values. For the leakage flux, the curve is obtained and shown in figure 6 . The measured values can be represented by a $3^{\text {rd }}$-order polynomial function, which enables us to calculate the leakage inductances defined in Eqs. (10) and (11). The calculated inductances are shown in figure 7.

Finally, taking the magnetizing flux and leakage flux saturations into account, Eq. (13) represents the system equations in an arbitrary reference frame rotating at a speed of $\omega$ for a three-phase squirrel cage induction machine. From this equation, the equivalent circuit of the machine is obtained as shown in figure 8. Contrary to the conventional model, in this equivalent circuit the inductances are varied according to their exciting currents. In simulation, the stationary reference frame is chosen as the reference frame since it yields simpler transformation matrices. In addition, the present study focuses on the stator transients.

$$
\left[\begin{array}{c}
v_{q s} \\
v_{d s} \\
0 \\
0
\end{array}\right]=[Z]\left[\begin{array}{c}
i_{q s} \\
i_{d s} \\
i_{q r}^{\prime} \\
i_{d r}^{\prime}
\end{array}\right]
$$

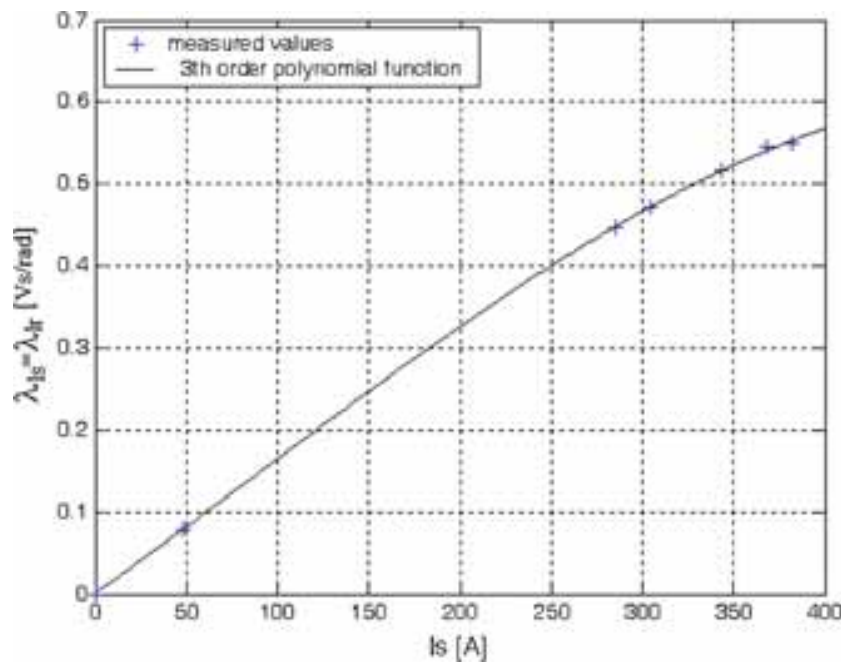

Figure 6. Leakage flux curve of tested induction machine. 


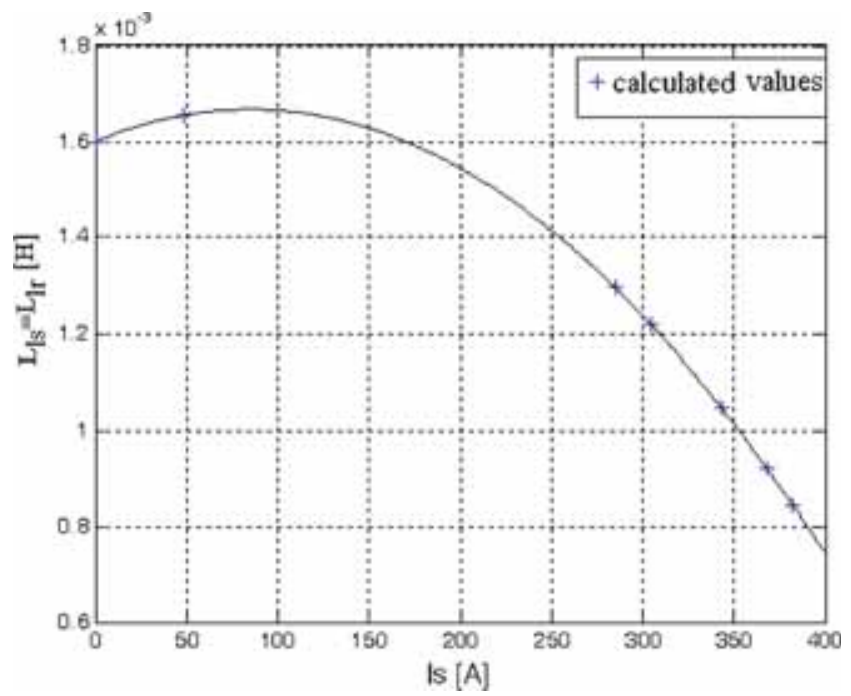

Figure 7. Variations of calculated leakage inductances versus stator current.

where

$$
[Z]=\left[\begin{array}{llll}
R_{\mathrm{s}}+p\left(l_{l s}+L_{q-q m}\right) & \omega \cdot L_{s}+p \cdot L_{q-d m} & p \cdot L_{q-q m} & \omega \cdot L_{m}+p \cdot L_{q-d m} \\
-\omega \cdot L_{s}+p \cdot L_{d-q m} & R_{s}+p\left(l_{l s}+L_{d-d m}\right) & -\omega \cdot L_{s}+p \cdot L_{d-q m} & p \cdot L_{d-d m} \\
p \cdot L_{q-q m} & \left(\omega-\omega_{r}\right) L_{m}+p \cdot L_{q-d m} & R_{r}^{\prime}+p\left(l_{l r}^{\prime}+L_{q-q m}\right) & \left(\omega-\omega_{r}\right) L_{r}^{\prime}+p \cdot L_{q-d m} \\
\left(\omega-\omega_{r}\right) L_{m}+p \cdot L_{d-q m} & p \cdot L_{d-d m} & \left(\omega_{r}-\omega\right) L_{l r}^{\prime}+p \cdot L_{q-d m} & R_{r}^{\prime}+p\left(l_{l r}^{\prime}+L_{d-d m}\right)
\end{array}\right]
$$

and, p=d/dt, $L_{\mathrm{s}}=L_{\mathrm{ls}}+L_{\mathrm{m}}, L_{\mathrm{r}}=L_{\mathrm{lr}}^{\prime}+L_{\mathrm{m}}$.

The dynamic equation of the rotating part can be expressed by (14). In this equation, $J$ represents the total inertia of the rotating part referred to the machine shaft.

$$
\frac{2 \mathrm{~J}}{\mathrm{P}} \cdot \frac{\mathrm{d} \omega_{\mathrm{r}}}{\mathrm{dt}}+\mathrm{F} \cdot \omega_{\mathrm{r}}=\mathrm{T}_{\mathrm{elm}}-\mathrm{T}_{\mathrm{L}}
$$

For our mechanical model, the electromagnetic torque is a required parameter. The developed torque by the machine is given by the following equation:

$$
T_{\mathrm{elm}}=\frac{3}{2} \cdot \frac{P}{2} \cdot \mathrm{L}_{\mathrm{m}}\left(\mathrm{i}_{\mathrm{qs}} \cdot \mathrm{i}_{\mathrm{dr}}^{\prime}-i_{\mathrm{ds}} \cdot \mathrm{i}_{\mathrm{qr}}^{\prime}\right) .
$$

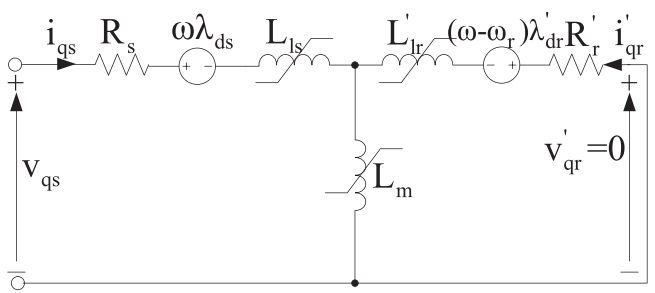

(a) q-axis

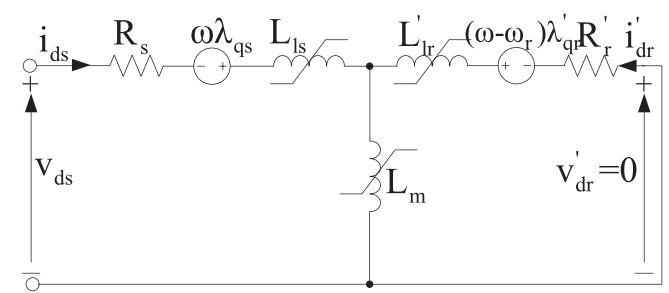

(b) d-axis

Figure 8. Equivalent circuits of the induction machine considering saturation effects. 


\section{Modelling of the mechanical part}

A detailed kinematics breakdown is made using every rotational degree of freedom (DOF) of the drive chain. This results in a 6-DOF model for the mechanical part which facilitates the calculation of the inertial and the elastic properties of the system. Based on the 6-DOF model, a simplified model is created which ignores the flexibilities gearbox bearings. This model has 4DOF and is shown schematically in figure 9. The following description applies to 4-DOF model elements:

- DOF No: 1 Motor output shaft

- DOF No: 2 Gearbox wheel

- DOF No: 3 Gearbox pinion

- DOF No: 4 DC machine input shaft

The motion equations in the development of a dynamic model are derived using Lagrange's equations. The general form of these equations is given by the following equation (Sakman et al 2005).

$$
\frac{\mathrm{d}}{\mathrm{dt}}\left(\frac{\partial \mathrm{E}_{\mathrm{k}}}{\partial \dot{\mathrm{q}}_{\mathrm{j}}}\right)-\frac{\partial \mathrm{E}_{\mathrm{k}}}{\partial \mathrm{q}_{\mathrm{j}}}+\frac{\partial \mathrm{E}_{\mathrm{p}}}{\partial \mathrm{q}_{\mathrm{j}}}=0 .
$$

where $E_{k}$ and $E_{p}$ are the system kinetic and potential energy, respectively; $q$ is the generalized coordinates and; $\dot{\mathrm{q}}$ represents the derivative of $\mathrm{q}$ with respect to time.

The total kinetic energy of the system is represented by the moving inertias, given by the following equation:

$$
E_{k}=\frac{1}{2}\left[J_{m} \cdot \dot{\theta}_{m}^{2}+J_{w} \cdot \dot{\theta}_{w}^{2}+J_{p} \cdot \dot{\theta}_{p}^{2}+J_{L} \cdot \dot{\theta}_{L}^{2}\right]
$$

The total potential energy of the system is accumulated in the elements on the account of their elasticity and is given by the following equation:

$$
\begin{aligned}
E_{p}=\frac{1}{2}[ & k_{w p}\left(r_{w} \cdot \theta_{w}-r_{p} \cdot \theta_{p}\right)^{2}+k_{s 1}\left(\theta_{w}-\theta_{m}\right)^{2} \\
& \left.+k_{s 2}\left(\theta_{p}-\theta_{L}\right)^{2}+k_{c 1}\left(\theta_{w}-\theta_{m}\right)^{2}+k_{c 2}\left(\theta_{p}-\theta_{L}\right)^{2}\right] .
\end{aligned}
$$

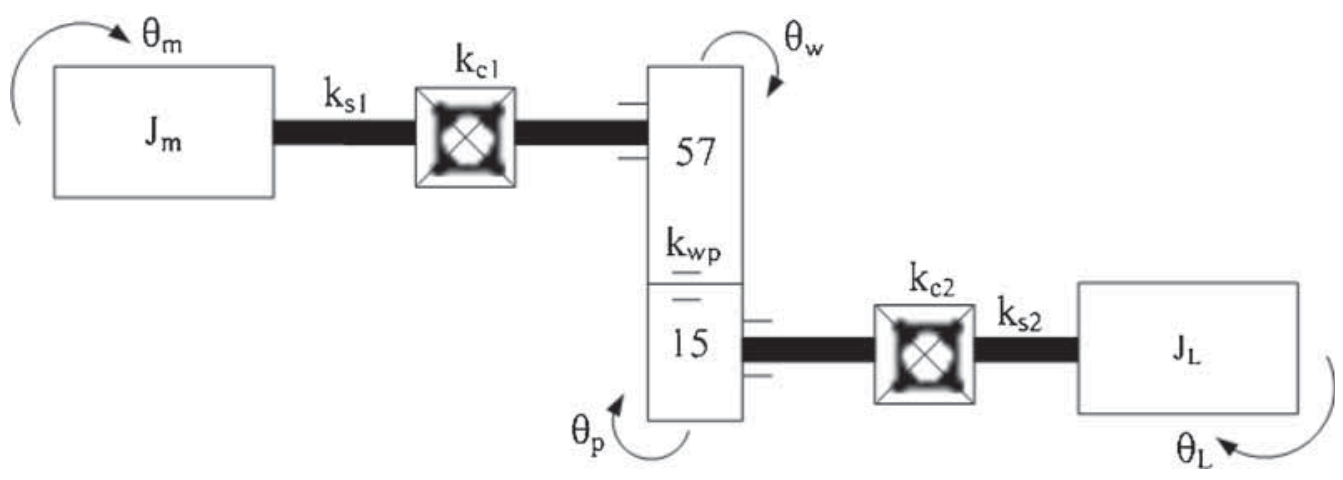

Figure 9. Kinematics chain 4 degree of freedom model schematic diagram. 
If the Lagrange equation (16) is applied to the energy expressions, and that individual equations are organized in a matrix form, then we have:

$$
\mathrm{M} \cdot \ddot{\mathrm{q}}+\mathrm{K} \cdot \mathrm{q}=\mathrm{T} \text {. }
$$

where $\mathrm{M}$ is the diagonal matrix of inertias and $\mathrm{K}$ is the elasticity matrix:

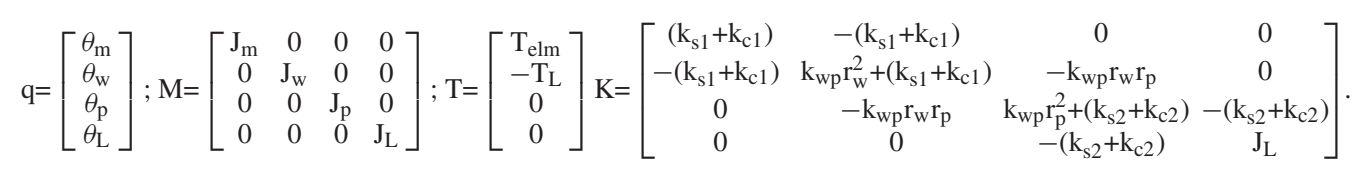

\section{Simulation of the complete model}

A flow-chart to solve the state-space equations is presented in figure 10. The developed models for the electrical part and the mechanical part are implemented respectively in SIMULINK ${ }^{\circledR}$ and ITI ${ }^{\circledR}$-SIM. Each element of the kinematics chain in the mechanical model shown in figure 11 is represented by their inertias and constants of elasticity.

The co-simulation is initiated by launching the SIMULINK ${ }^{\circledR}$ file that takes the speed data generated by the ITI ${ }^{\circledR}$-SIM model as input variables. Likewise, the ITI ${ }^{\circledR}$-SIM model receives the electromagnetic torque data from the SIMULINK ${ }^{\circledR}$ model to calculate the speed of the shaft. Consequently, the data exchanges take place mutually between these simulation environments through the communication elements ("Sender" and "Receiver" blocks). The exchange of data demands synchronization in two directions, and hence, a fixed-step solver is used.

SIMULINK ${ }^{\circledR}$ proposes five numerical integration methods: (i) the Dormand-Prince algorithm (ode5), (ii) the fourth-order Runge-Kutta algorithm (ode4), (iii) the Bogacki-Shampine algorithm (ode3), (iv) Heun's method (ode2), and (v) Euler's method (ode1). In order to choose an efficient integration method, these algorithms are tested. For this purpose, simulation time and precision are examined. The precision is determined by a performance index (PI) expressed by the following equation:

$$
\mathrm{PI}=\frac{1}{\mathrm{n}} \sum_{\mathrm{i}=1}^{\mathrm{n}}\left|\frac{\mathrm{y}_{\mathrm{i}}-\mathrm{y}_{\mathrm{i}}^{*}}{\mathrm{y}_{\mathrm{i}}}\right| .
$$

where $\mathrm{n}$ is the total number of data and $y_{i}, y_{i}^{*}$ represent the experimental and simulation results, respectively. This method has been evaluated for one-phase stator winding current results. The ECDS operating on $65 \%$ of the rated-load at rated frequency is simulated for $2 \mathrm{~s}$ on a Pentium-4 $\mathrm{PC}$ of $1.7 \mathrm{GHz}$ with a RAM of $1 \mathrm{~Gb}$. These test results are summarized in table 1 . The calculation step for the results obtained are $40 \mu$ s for the SIMULINK ${ }^{\circledR}$ model and $10 \mu$ s for the ITI ${ }^{\circledR}$-SIM model. The communication step herein is $40 \mu \mathrm{s}$.

It is evident from table 1 that Ode-1 solver gives the fastest simulation time. However, it has the least precise results. The method Ode-3 yields more divergent results in comparison to other three methods (Ode-2, Ode-4, Ode-5). The methods Ode-2 and Ode-5 give the most precise results. The discrepancy of the results for these two methods is fairly small $(1.42 \%)$. Though Ode-5 gives more precise results than those of Ode-2, the method Ode-2 provides less 


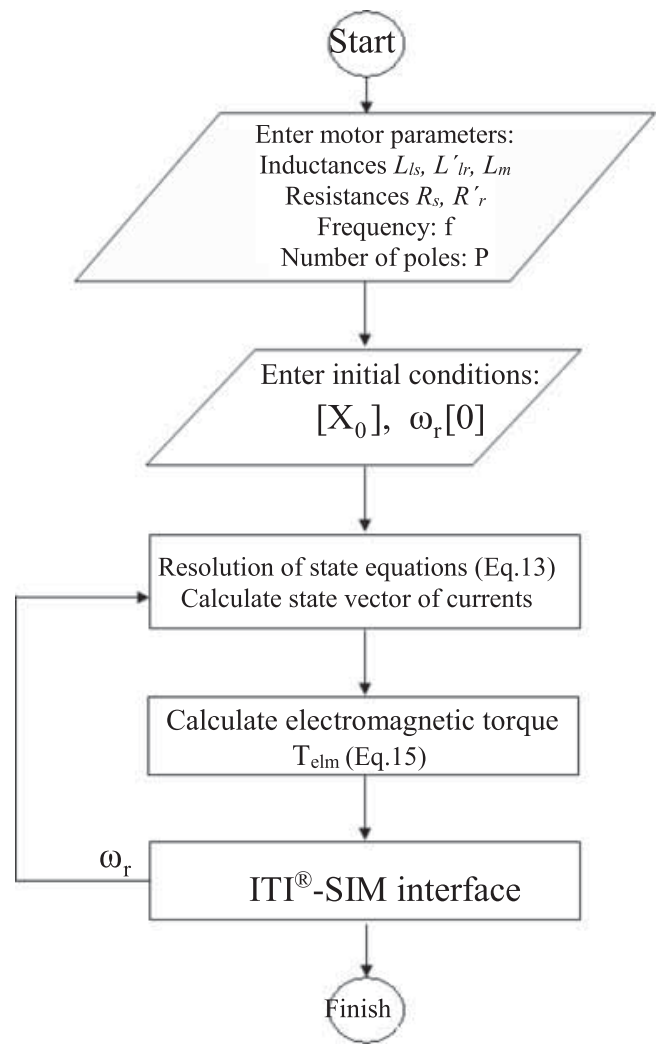

Figure 10. The flow-chart of the simulation program for the complete ECDS.

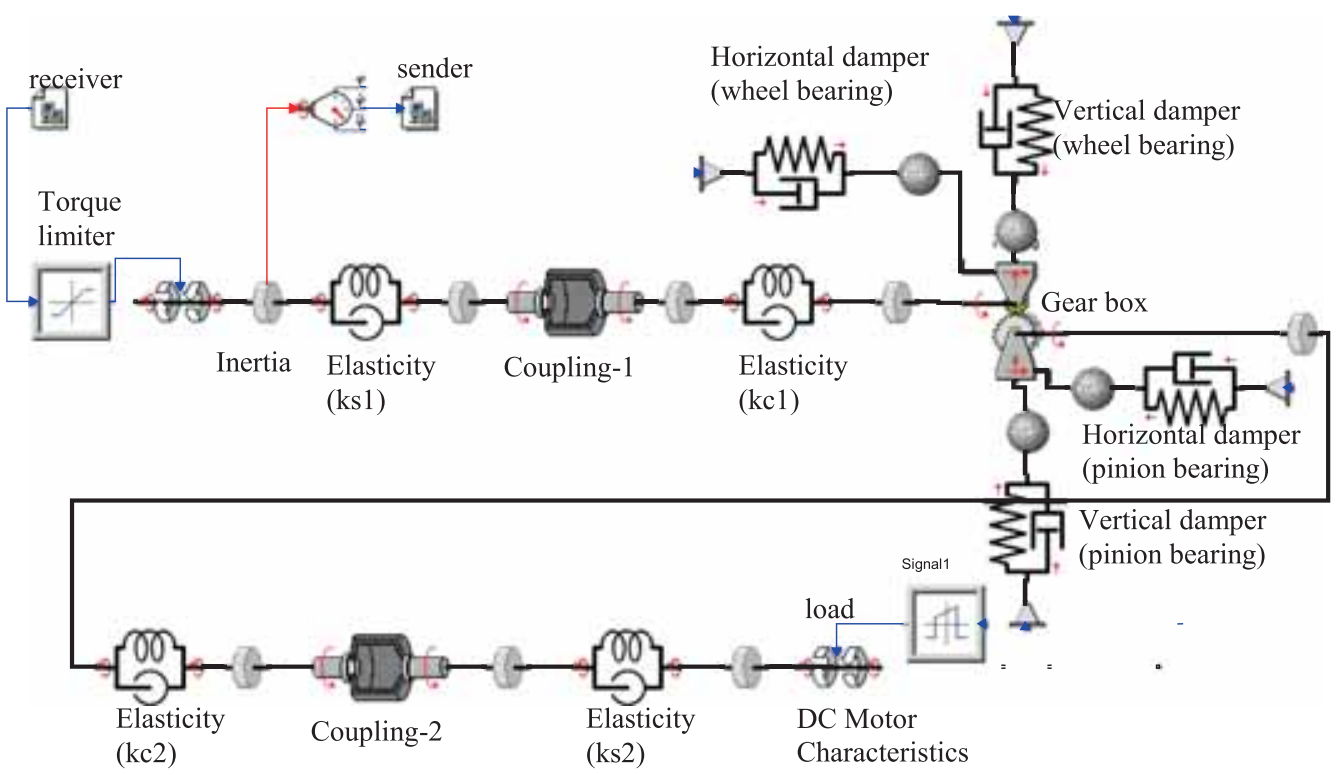

Figure 11. Implementation of the mechanical part model in ITI ${ }^{\circledR}$-SIM. 
Table 1. Simulation time and PI with respect to fixed-time integration methods for the simulated time of $2 \mathrm{~s}$.

\begin{tabular}{lcc}
\hline $\begin{array}{l}\text { Resolution } \\
\text { methods }\end{array}$ & $\begin{array}{c}\text { Simulation } \\
\text { time [s] }\end{array}$ & PI (\%) \\
\hline Ode-1 & 319 & 25.058 \\
Ode-2 & 366 & 14.396 \\
Ode-3 & 418 & 24,127 \\
Ode-4 & 453 & 16.768 \\
Ode-5 & 551 & 12.976 \\
\hline
\end{tabular}

Table 2. Co-simulation parameters.

\begin{tabular}{|c|c|c|c|c|}
\hline $\begin{array}{l}\text { Resolution } \\
\text { method }\end{array}$ & $\begin{array}{l}\text { Calculation step } \\
\text { (SIMULINK }^{\circledR} \text { ) }\end{array}$ & $\begin{array}{c}\text { Calculation step } \\
\text { (ITI }{ }^{\circledR} \text {-SIM) }\end{array}$ & $\begin{array}{c}\text { Communication } \\
\text { step }\end{array}$ & $\begin{array}{c}\text { Communication } \\
\text { delay }\end{array}$ \\
\hline Ode-2 & $40 \mu \mathrm{s}$ & $10 \mu \mathrm{s}$ & $40 \mu \mathrm{s}$ & One step $(40 \mu \mathrm{s})$ \\
\hline
\end{tabular}

simulation time than that of Ode-5. As a result, the method Heun's algorithm Ode-2 is chosen for the ECDS model simulation. On the other hand, ITI ${ }^{\circledR}$-SIM solver automatically selects the numeric integration method and allows the user to define only simulation parameters such as minimum and maximum calculation step, maximum relative error, etc.

In simulation, the choice of a calculation step is another important parameter that should be taken into account. In order to be able to observe rotor dynamics, the calculation step must be much smaller than machine time constant. Time constant of the rotor is calculated as follows:

$$
\tau=\frac{L_{r}^{\prime}}{R_{r}^{\prime}}
$$

The generated/acquired signals have a frequency of $25 \mathrm{kHz}$ which corresponds to $40 \mu \mathrm{s}$. Therefore, $40 \mu \mathrm{s}$ is taken as the calculation step for the SIMULINK ${ }^{\circledR}$ model. It is observed that the co-simulation is only valid on condition that ITI ${ }^{\circledR}$-SIM calculation step is equal or lower than Communication step as well as calculation step for the SIMULINK ${ }^{\circledR}$ model. This coordination of communication speed is vital to synchronize the calculation process. Moreover, the communication step must be integer-multiples of the ITI ${ }^{\circledR}$-SIM calculation step. Finally, 10 $\mu \mathrm{s}$ is taken as the calculation step for the ITI ${ }^{\mathbb{R}}$-SIM model. One step delay is inherently present between the tools. It must also be noted that the simulated time for two simulation environments must be the same. The co-simulation parameters are summarized in table 2.

\section{Simulation and experimental results}

\subsection{Parameter determination}

A three-phase induction machine of $55 \mathrm{~kW}$ has been configured for experimental study and a data acquisition system has been installed (figure 12). Three stator currents and voltages, speed and 

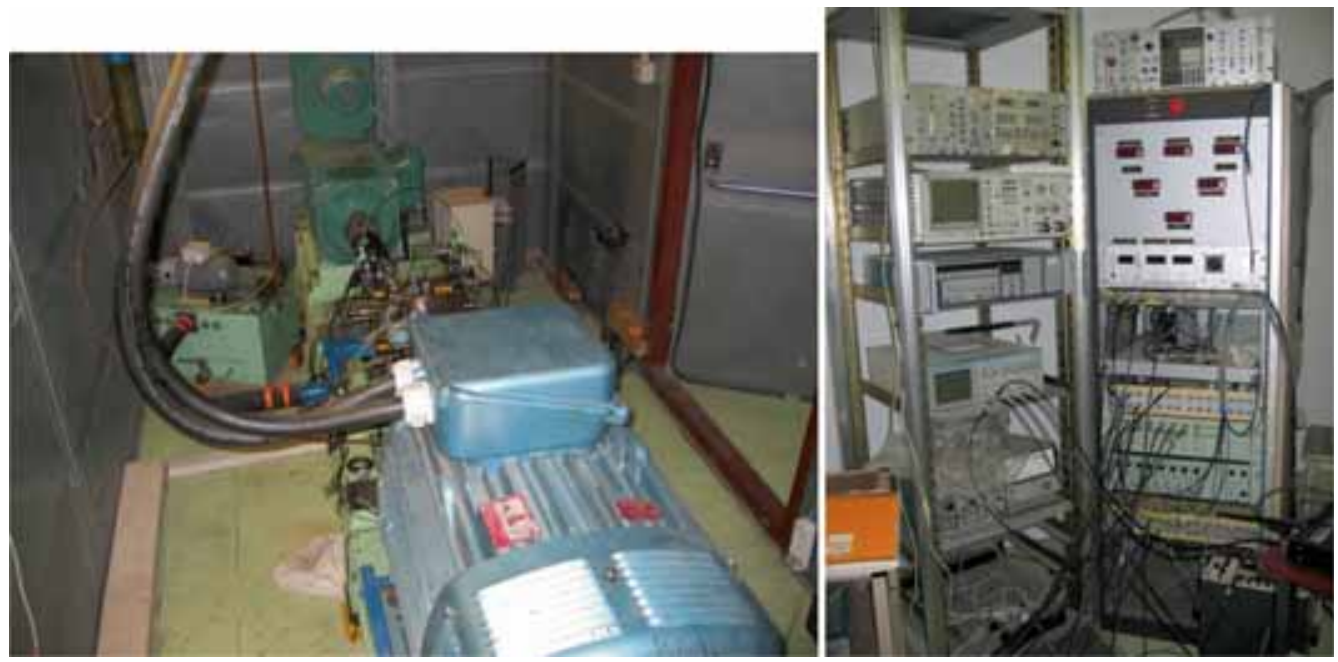

Figure 12. Test bed of the examined ECDS and its measurement system.

motor torque are measured. The speed and torque are measured on the load side. Two types of motor operation are studied: (i) Line starting, and (ii) Supply with soft starter. The soft starter is a variable-frequency induction machine drive with V/f control. The DC bus voltage of the starter

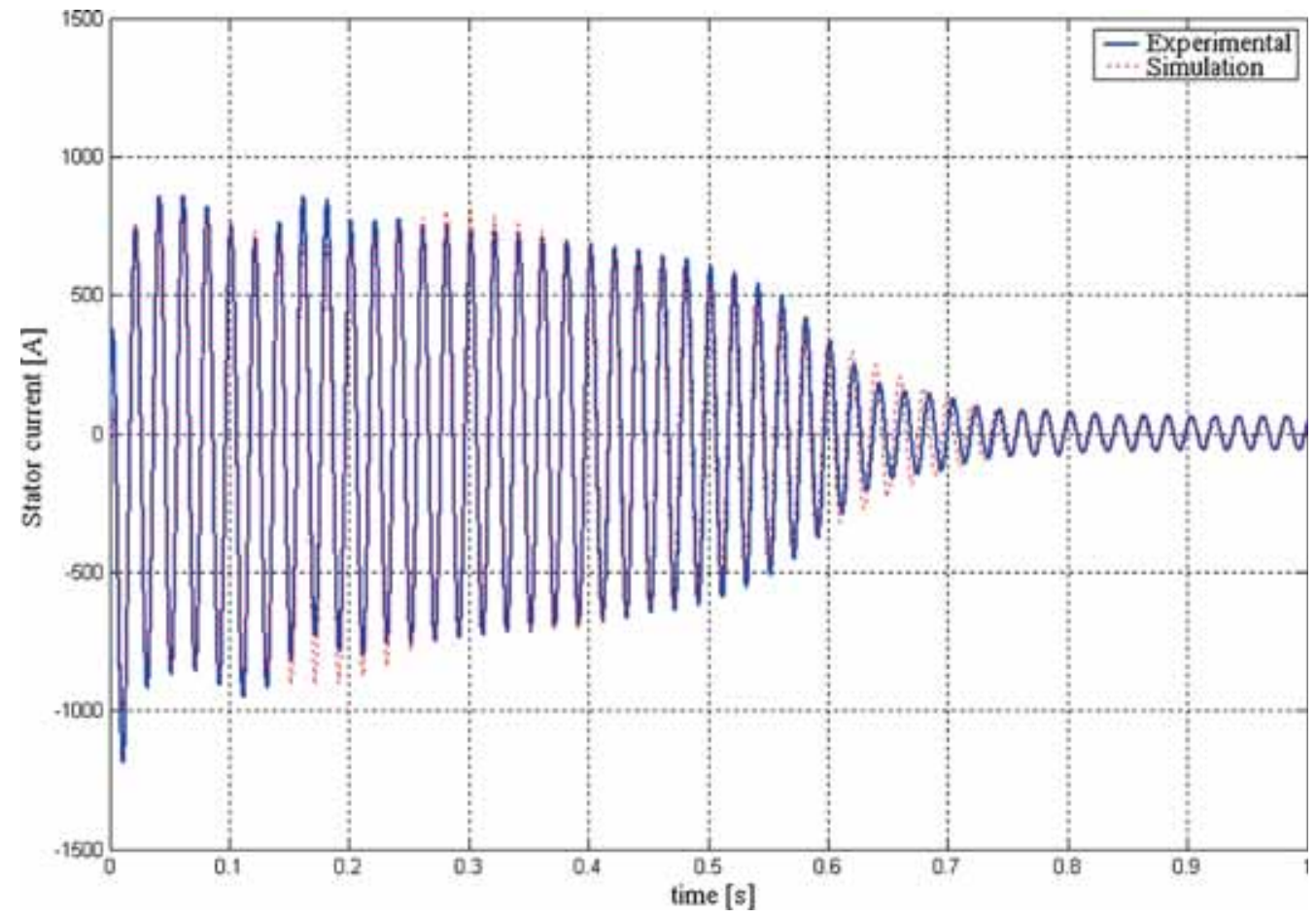

Figure 13. Comparison of one-phase stator current at no-load operation for line starting. 
is fed by a 3-phase diode rectifier. The output voltage and frequency control are acquired by using the pulse width modulation (PWM) techniques. The switching frequency of the inverter is $2 \mathrm{kHz}$. The voltage-versus-frequency pattern of the drive is a ramp function. For the experimental study, the acceleration ramp is selected as $1 \mathrm{~s}$.

The parameters of the drive machine are determined by the performed tests complying with IEEE Std 112-1996 (IEEE Std. 112-1996 1996). The parameters of some mechanical elements such as torque limiter and couplings on the kinematics chain are provided by the manufacturer. The calculated and provided electrical and mechanical parameters are given in Appendix.

\subsection{Simulation and experimental results}

First, the transient performance for line starting is simulated. We made a comparison between simulated and experimental results of one-phase stator phase current and rotor speed. Figure 13 and figure 14 demonstrate the comparison of no-load and rated load operations in transient regimes, respectively. For the no-load operation it is observed that most of correlation occurs on the point of current amplitude and starting time. The simulated peaks of transient currents are fairly lower than the experimental values. For the rated-load operation, the simulation results match fairly to the experimental ones. The simulated peaks of the inrush currents as well as the starting time are slightly higher than those of the experiment. The obtained results are always coherent for the steady-state operation. Finally, we conclude from these results that the proposed technique is valid and gives satisfactory performances for the transient and steady state regimes in case of line starting.

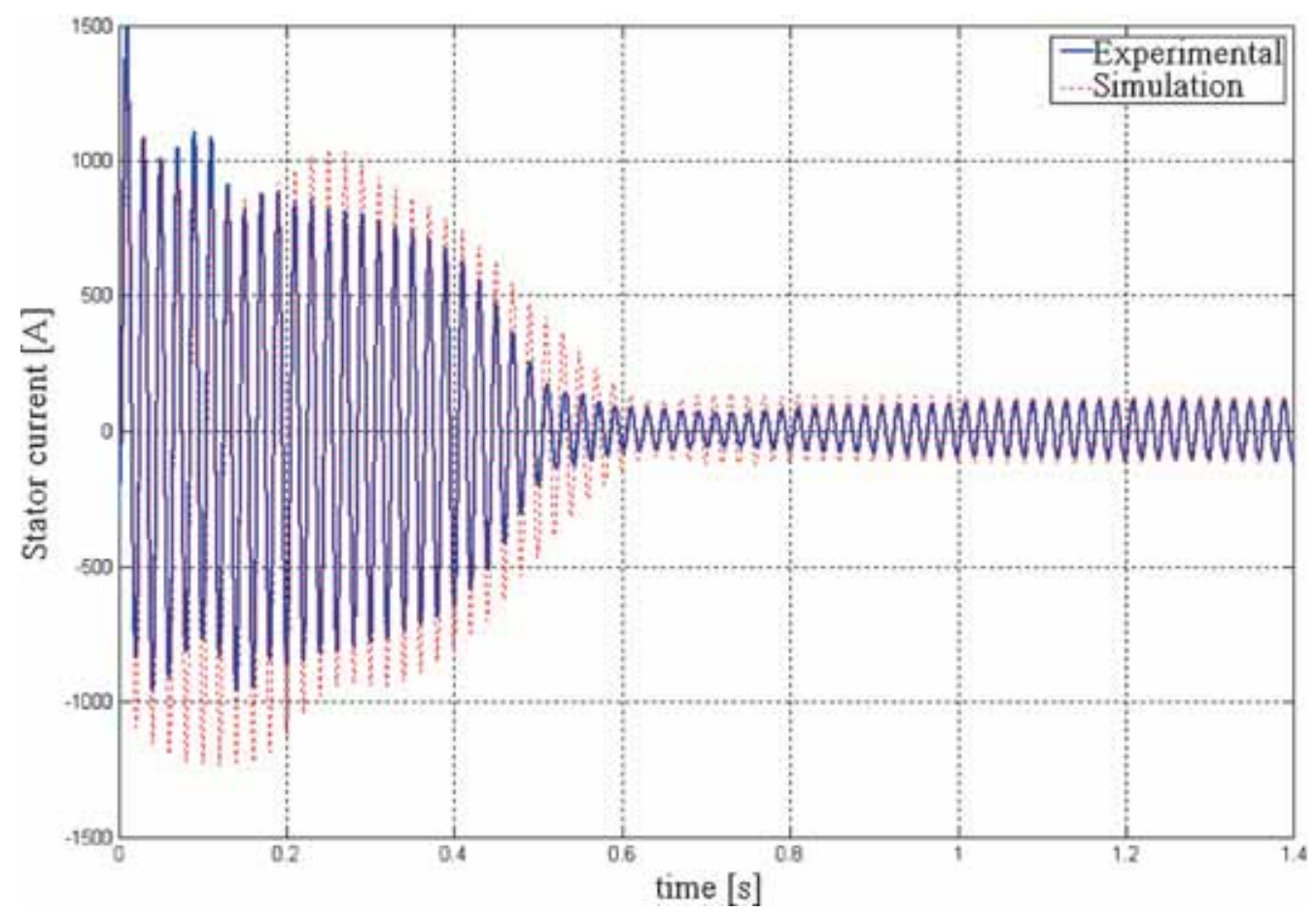

Figure 14. Comparison of one-phase stator current at rated-load operation for line starting. 

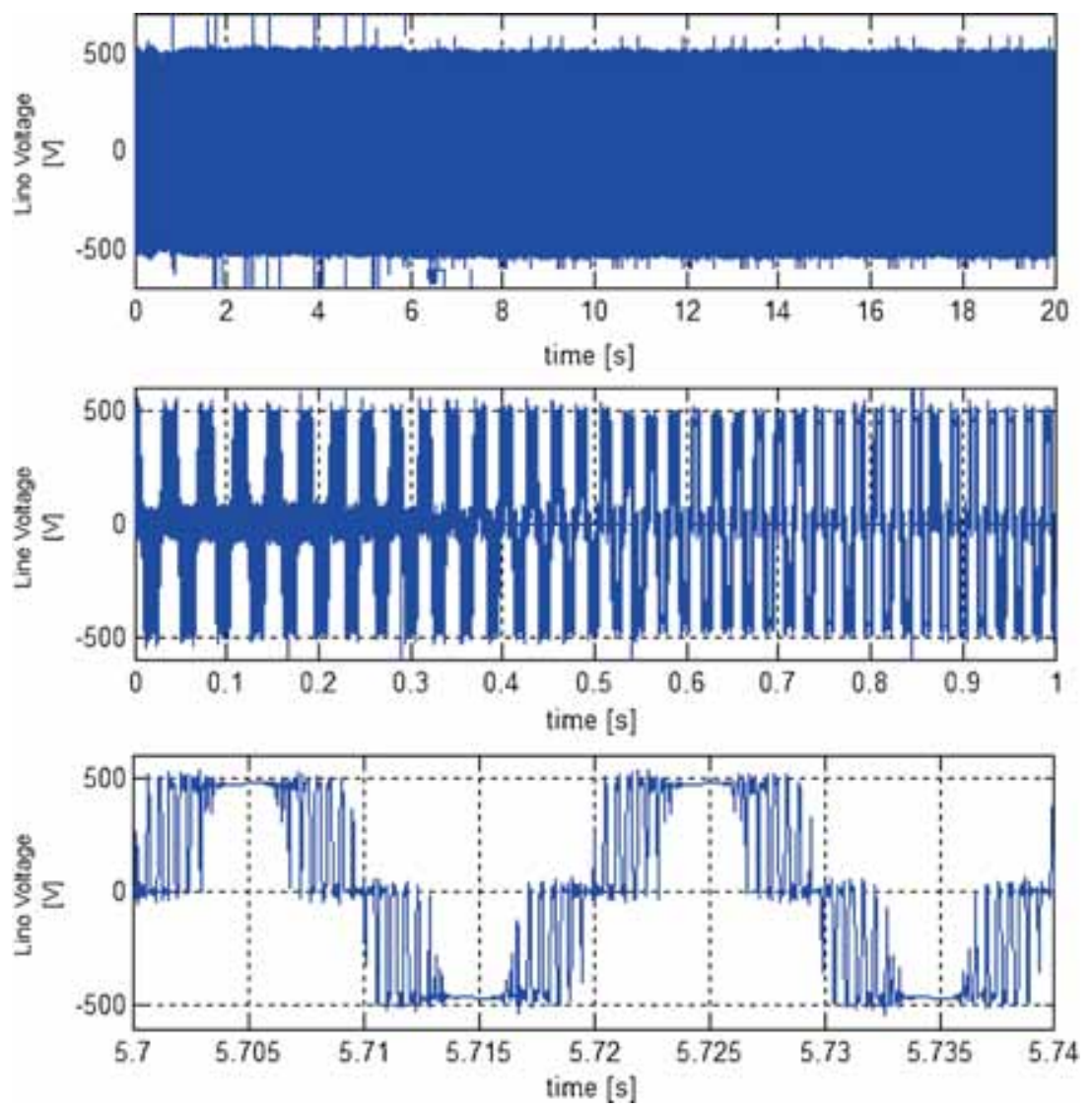

Figure 15. One-phase measured supply voltage for PWM inverter operation at $50 \mathrm{~Hz}$.

Secondly, the transient performance for the case supplied by PWM inverter is simulated. The complete ECDS is experimentally tested for different load and frequency levels such as $72 \%$ of rated load at $5 \mathrm{~Hz}, 77 \%$ of rated load at $20 \mathrm{~Hz}$, rated load at $30 \mathrm{~Hz}, 64 \%$ of rated-load at 50 Hz. We made comparisons between simulated and experimental results of load speed and onephase stator current. The results for an operation on $64 \%$ of rated-load at $50 \mathrm{~Hz}$ are given in figures 15-18. For the measured supply voltage shown in figure 15, the comparison of measured and simulated stator current is illustrated in figure 16. The simulated current for transient and steady-state regimes is given separately. The obtained results for both regimes are coherent. For the load torque given in figure 17, the simulated speed shown in figure 18 matches finely with the experimental one for the steady-state. However, it has many oscillations compared to the measured speed in transient regime.

\subsection{Discussion on oscillations in the speed}

There are severe oscillations in the simulated speed in the transient regime (figure 18b). Oscillations in the speed transient are also observed for line starting (figure 19); however, they are not as 

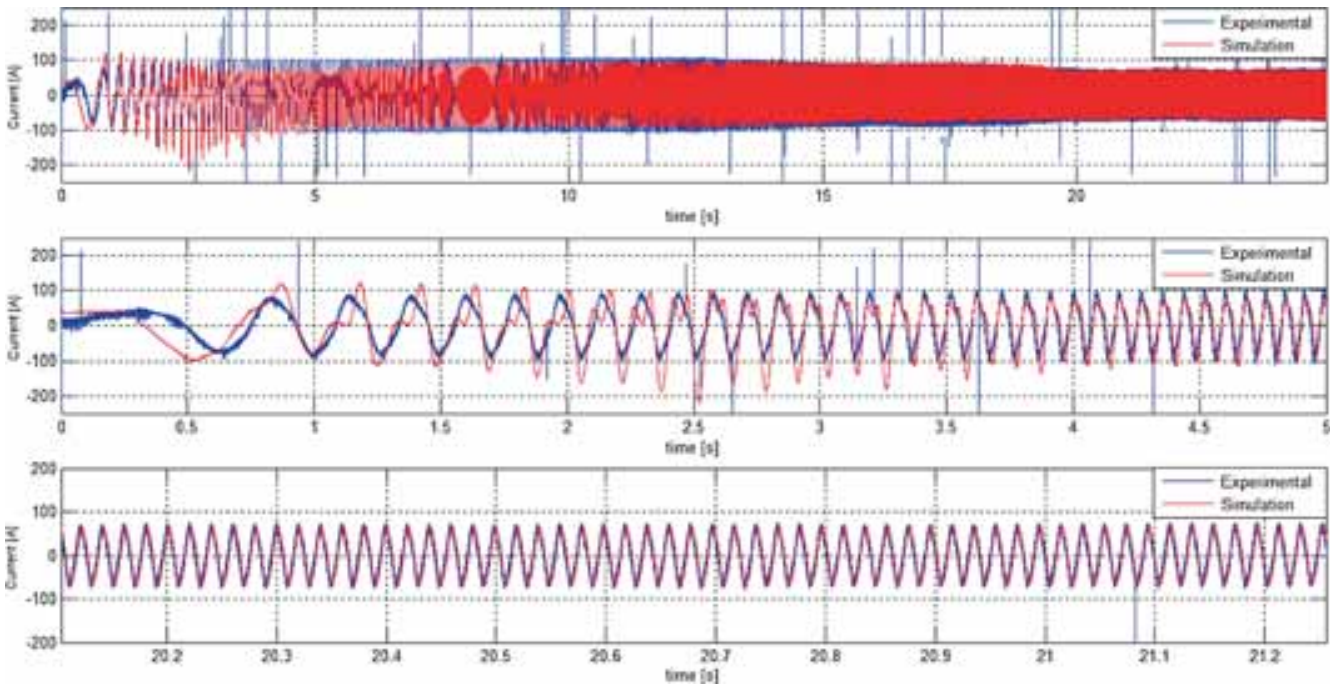

Figure 16. Comparison of the stator current for PWM inverter operation at $50 \mathrm{~Hz}$ (overall view and zoomed in transient and steady-state regimes respectively).

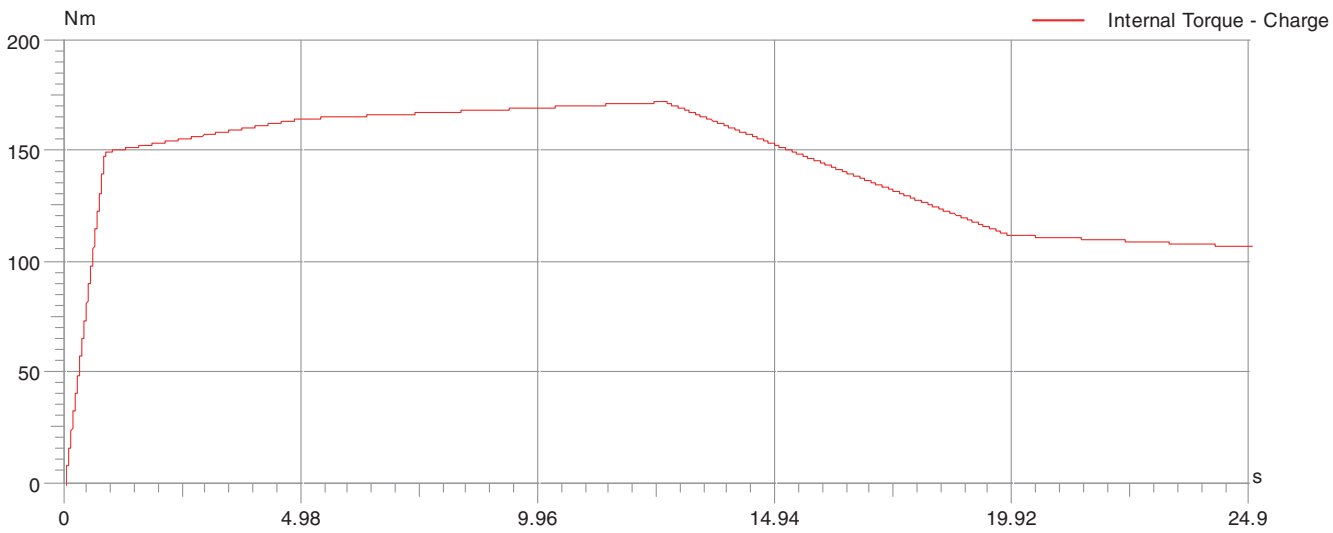

Figure 17. Simulated torque on the load side for PWM inverter operation.

many as those occurring in PWM operation. Furthermore, the oscillations are very light at lower speeds (figure 20).

The oscillations are due to two main reasons. The first reason is the determination of damping coefficients of the elements in the kinematics chain. Elastic and damping behaviour are occurred between rotating mechanical elements. They can be modelled in ITI-SIM using "spring-damper" element, which is called "elasticity" in figure 11. The potential energy is the energy in the "spring" element, which is calculated in accordance with Eq. (22) while the energy loss is 


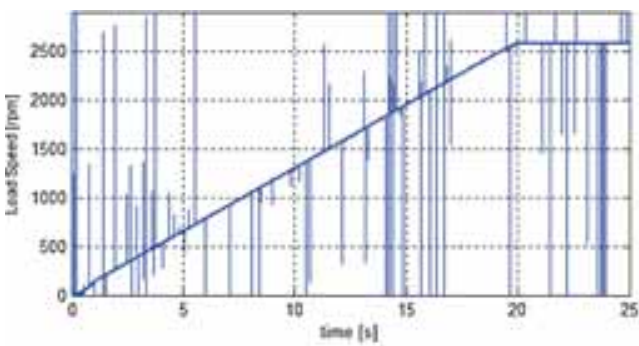

(a)

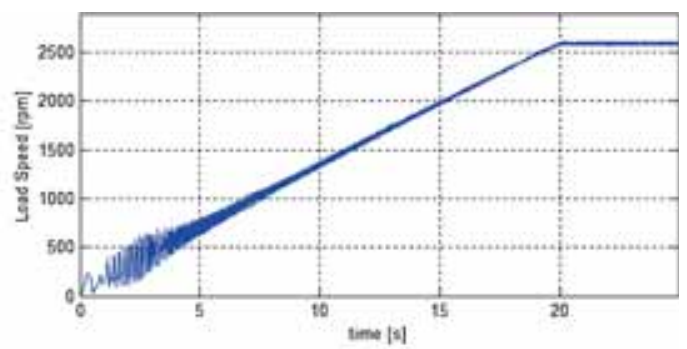

(b)

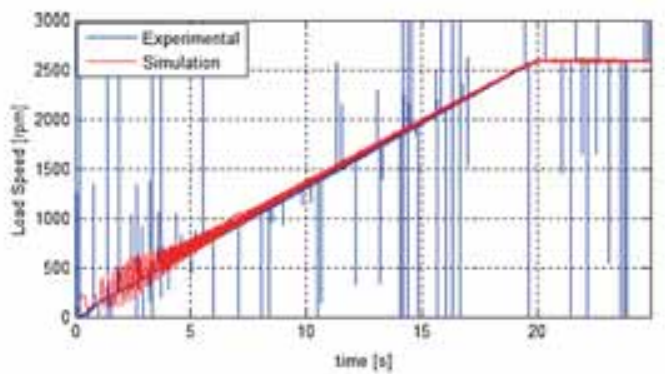

(c)

Figure 18. Load speed results for PWM inverter operation at $50 \mathrm{~Hz}$. (a) Experimental results. (b) Simulation results. (c) Comparison of the experimental and simulation results.

the energy of the damper, which is calculated by Eq. (23) (Sakman et al 2005; ITI ${ }^{\circledR}$-SIM 1999).

$$
E_{p}=\int T_{\text {spring }} d \theta
$$

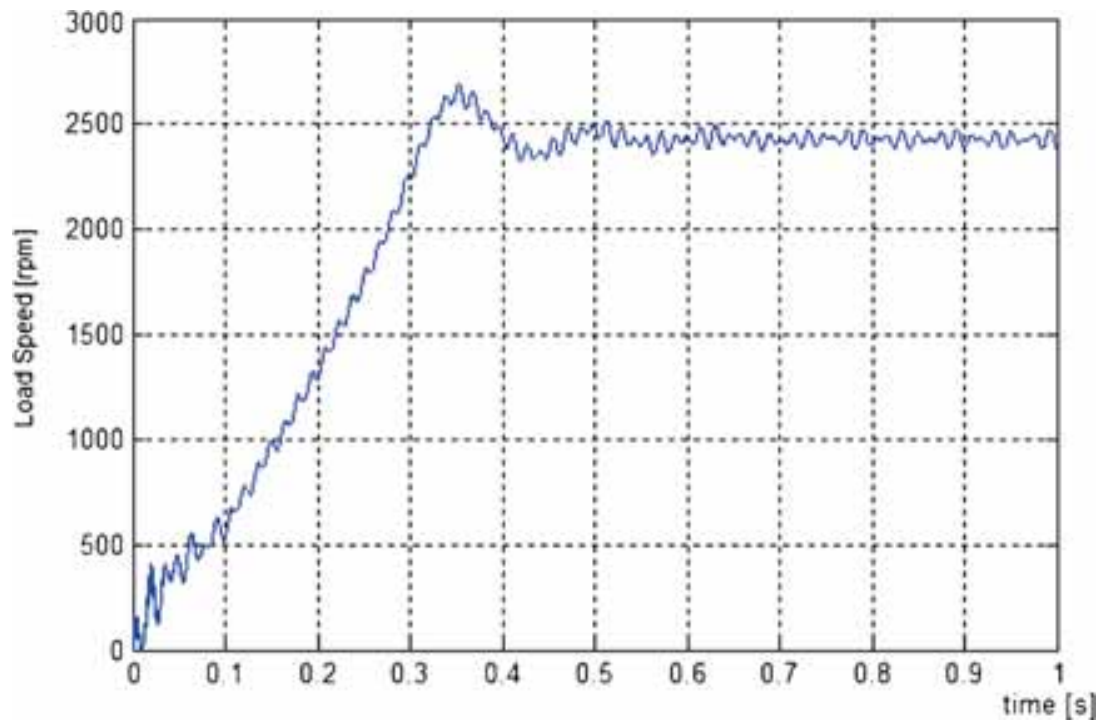

Figure 19. Load speed variation at $75 \%$ of rated load for line starting operation. 


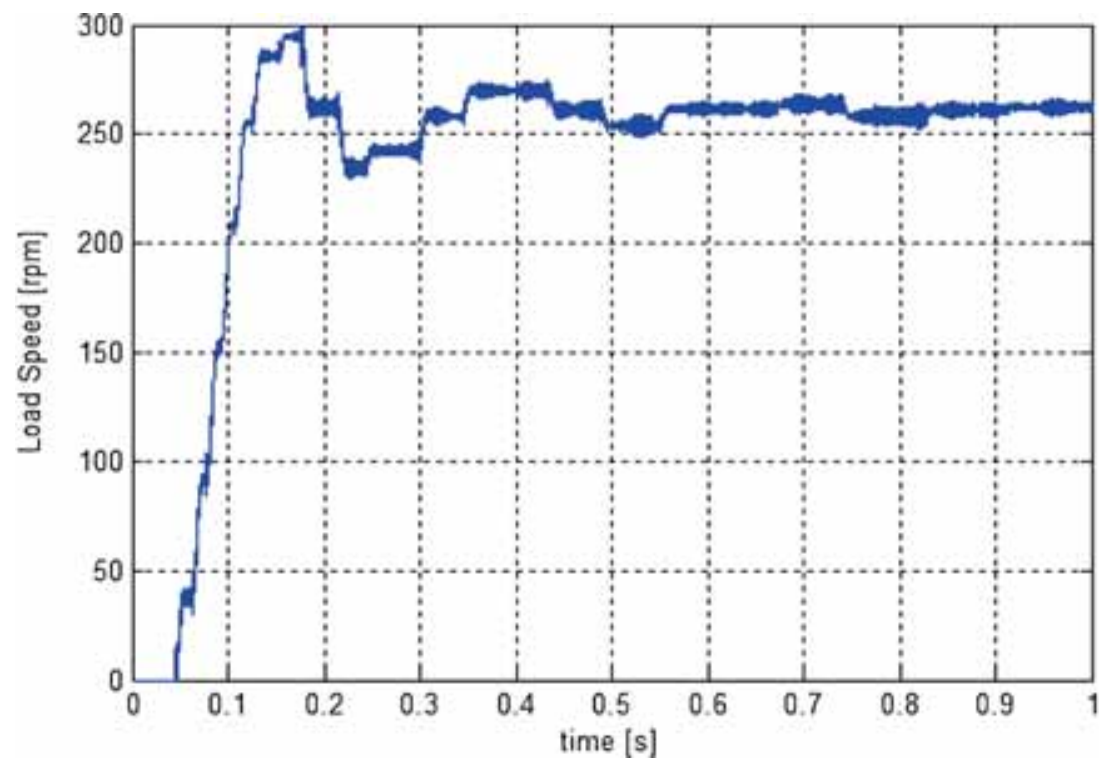

Figure 20. Load speed for PWM inverter operation at no-load (5 Hz).

$$
E_{\text {losses }}=\int T_{\text {damper }} d \omega
$$

While the internal torque of the spring is calculated with elasticity factor $(\mathrm{k})$, the internal torque of the damper is calculated with damping coefficient (b) as follows,

$$
\begin{aligned}
T_{\text {spring }} & =k \cdot\left(\theta_{1}-\theta_{2}\right) . \\
T_{\text {damper }} & =b \cdot\left(\omega_{1}-\omega_{2}\right) .
\end{aligned}
$$

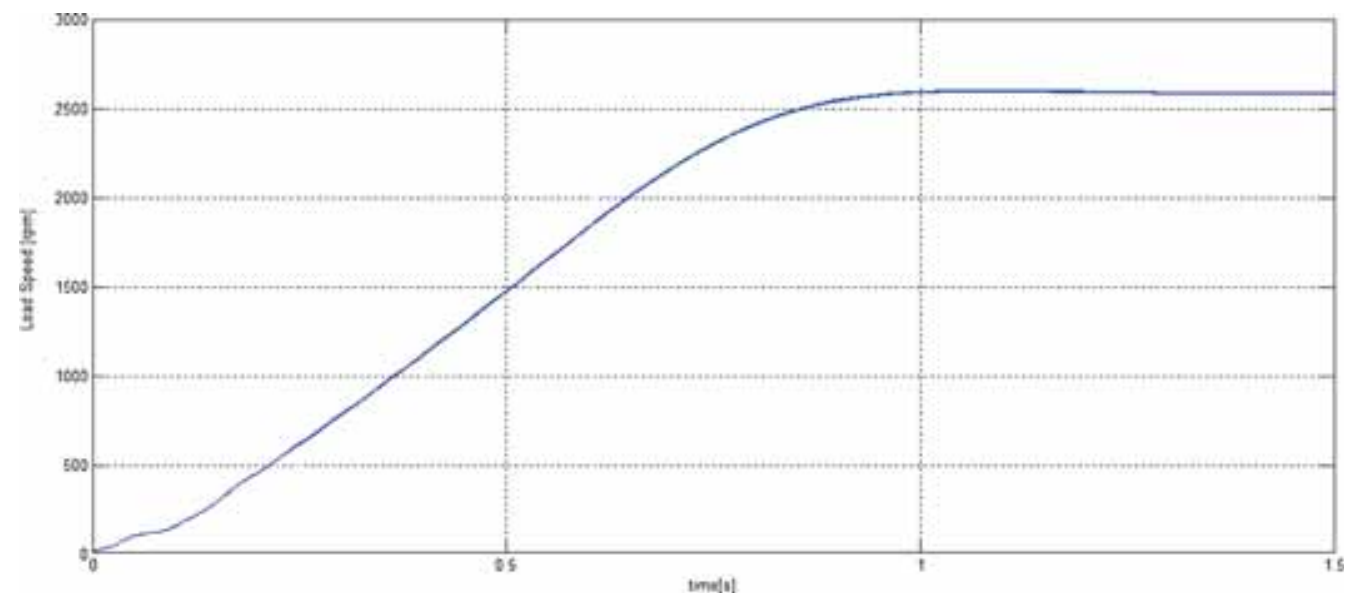

Figure 21. Load speed for PWM inverter operation at $64 \%$ of rated-load, $50 \mathrm{~Hz}$ (without Co-simulation). 
Since the damping coefficients for the elements in the kinematics chain are not available, we consider only the elasticity behaviour in the mechanical model (figure 11). If the damping coefficients of the mechanical elements are considered, then that will contribute to the decrease in the oscillations in the speed.

The second reason of the oscillations in the speed is the differential calculus in the calculation basis of some mechanical elements' models in ITI-SIM. The rotational angle of the kinematics chain is being solved and used to calculate the rotational speed in the ITI-SIM. The difference between the rotational angles of the two sides of the coupling-1 is very big at the starting phase. That makes the speed oscillate. When we simulated the motor drive model with a simplified mechanical model that means considering only inertia, friction factor and a constant load i.e. without co-simulation, we did not observe the severe oscillations in the simulated rotor speed (figure 21). In this case, the rotor speed is obtained from the output of an integrator according to Eq. (14).

To eliminate the oscillations in transient phase, the mechanical part model should be improved taking the damping coefficients of the mechanical elements into account. For the perfect matching between simulated and experimental results in transient regimes, the drive model should also be improved. If the rotor blocked test is carried out for more voltage values, the leakage flux variations with respect to the stator current will be represented by high order polynomial function. Thus, the leakage flux saturation model is improved, which will increase the drive model performance in transient regime.

\section{Conclusion}

In this paper, an improved methodology is presented and verified experimentally for modelling and simulating ECDSs. In practice, the use of the proposed methodology is based on domain-based simulators individually, namely electric and mechanical part simulators, and also on integrating these two parts with a co-simulation. Besides, an accurate dynamic drive model considering the saturation effects was developed to examine the machine behaviour in transient regimes precisely. Simulated and experimental results were presented and found to be in satisfactory correlation. However, we observed oscillations on the speed transient. The oscillations are mainly due to the determination of damping coefficients of the elements in the kinematics chain, and the differential calculus in the calculation basis of some mechanical elements' models in ITI-SIM. To avoid the oscillations in the speed transient, damping coefficients of the elements will be considered in the future studies. Other simulation environments with possible integration of Matlab/SIMULINK for co-simulation based modelling will also be sought.

In conclusion, the results prove that the proposed methodology as well as the developed models is satisfactory and viable for modelling and simulating of an entire ECDS. The approach proposed in this paper can be applied by engineers working on the design phase of elements in multi-domain systems such as ECDSs.

\section{Acknowledgements}

The authors would like to thank Dr. N. Martin for her collaboration in facilitating the utilization and providing data measurements from the GOTIX Experimental Test Bed. Part of this work is founded by a grant from Regional Council of Picardie, under a support project naming "Modelling in Engineering Sciences". 


\section{Appendixes}

\begin{tabular}{|c|c|c|}
\hline \multicolumn{3}{|c|}{ Electrical characteristics of induction machine of $55 \mathrm{~kW}$} \\
\hline Rated voltage & $380 / 660 \mathrm{~V}$ & \\
\hline Number of poles & 8 & \\
\hline Connection & Delta & \\
\hline Frequency & $50 \mathrm{~Hz}$ & \\
\hline Rated Speed & $736.6 \mathrm{rpm}$ & \\
\hline Stator resistance & $0.1728 \Omega$ & \\
\hline Stator leakage reactance & $0.6797 \Omega$ & \\
\hline Rotor resistance & $0.1012 \Omega$ & \\
\hline Rotor leakage reactance & $1.3101 \Omega$ & \\
\hline Magnetizing reactance & $13.24 \Omega$ & \\
\hline Resistance representing ccore losses & $276.8 \Omega$ & \\
\hline Inertia of rotor & $2.34 \mathrm{kgm}^{2}$ & \\
\hline Rated torque $\left(\mathrm{T}_{\text {elm }}\right)$ & $713.1 \mathrm{Nm}$ & \\
\hline Kinematics chain elements & Inertia $\left(\mathrm{kg} \cdot \mathrm{m}^{2}\right)$ & Elasticity $(\mathrm{Nm} / \mathrm{rad})$ \\
\hline Torque limiter & 0.1604 & - \\
\hline Transmission shaft $n^{\circ} 1$ & $1.544 \times 10^{-3}$ & $5.5571 \times 10^{6}$ \\
\hline Coupling $n^{\circ} 1$ & $15.209 \times 10^{-3}$ & $0.25 \times 10^{6}$ \\
\hline Wheel shaft & $2.9101 \times 10^{-4}$ & 83785.368 \\
\hline Wheel (57 teeth) & $5.2499 \times 10^{-3}$ & \\
\hline Pinion with shaft (15 teeth) & $1.877 \times 10^{-4}$ & 53370.17 \\
\hline Transmission shaft $n^{\circ} 2$ & $2.0549 \times 10^{-3}$ & $2.72 \times 10^{6}$ \\
\hline Coupling $n^{\circ} 2$ & $16.495 \times 10^{-3}$ & $0.25 \times 10^{6}$ \\
\hline Torque meter & $1.2 \times 10^{-3}$ & $4.74 \times 10^{6}$ \\
\hline
\end{tabular}

\section{Nomenclature}

$\mathrm{q}, \mathrm{d}$ indices represent the magnitudes in $\mathrm{q}-\mathrm{d}$ axes respectively.

$\mathrm{v}_{\mathrm{qs}}, \mathrm{v}_{\mathrm{ds}}$ : stator voltages

$\mathrm{i}_{\mathrm{qs}}, \mathrm{i}_{\mathrm{ds}}$ : stator currents

$\mathrm{i}_{\mathrm{qr}}^{\prime}, \mathrm{i}_{\mathrm{dr}}^{\prime}$ : rotor currents

$\lambda_{\mathrm{qls}}, \lambda_{\mathrm{dls}}:$ stator leakage flux linkages

$\lambda_{\mathrm{qlr}}^{\prime}, \lambda_{\mathrm{dlr}}^{\prime}$ : rotor leakage flux linkages

$\lambda_{\mathrm{qm}}, \lambda_{\mathrm{dm}}$ : magnetizing flux linkages

$\mathrm{R}_{\mathrm{s}}, \mathrm{R}_{\mathrm{r}}^{\prime}$ : stator/rotor resistances, respectively

$\mathrm{L}_{\mathrm{ls}}, \mathrm{L}_{\mathrm{lr}}^{\prime}$ : stator/rotor leakage inductances, respectively

$\omega_{\mathrm{r}}, \omega_{\mathrm{e}}$ : rotor and supply voltage pulsations, respectively

$\mathrm{T}_{\mathrm{elm}}, \mathrm{T}_{\mathrm{L}}$ : electromagnetic and load torques, respectively

P: number of poles

F: friction factor

$\mathrm{J}_{\mathrm{m}}, \mathrm{J}_{\mathrm{L}}$ : drive motor and load inertias, respectively

$\mathrm{J}_{\mathrm{w}, \mathrm{Jp}}$ : inertias of wheel and pinion, respectively

$\theta_{\mathrm{m}}, \theta_{\mathrm{L}}$ : angular positions of drive motor and load inertias respectively 
$\theta_{\mathrm{w}}, \theta_{\mathrm{p}}$ : angular positions of wheel and pinion, respectively

$\mathrm{k}_{\mathrm{s} 1}, \mathrm{k}_{\mathrm{s} 2}$ : elasticity constants of the shafts associated with drive motor and load, respectively

$\mathrm{k}_{\mathrm{c} 1}, \mathrm{k}_{\mathrm{c} 2}$ : elasticity constants of the couplings associated with drive motor and load, respectively

$\mathrm{k}_{\mathrm{wp}}$ : equivalent elasticity constant between wheel and pinion teeth

$\mathrm{r}_{\mathrm{w}}, \mathrm{r}_{\mathrm{p}}$ : radius of the wheel and pinion, respectively

\section{References}

Boldea I and Nasar S A 1988 A general equivalent circuit (GEC) of electric machines including crosscoupling saturation and frequency effects. IEEE Trans. Energy Conversion 3(3): 689-695

Capolino G A and Henao H 1990 Design and simulation of power electronics converters control circuits using EMTP. IEEE Workshop on Computers in Power Electronics, pp. 47-61, August 5-7

Champagne R, Dessaint L A, Fortin-Blanchette H and Sybille G 2004 Analysis and validation of a real-time AC drive simulator. IEEE Trans. Power Electron 19(2): 336-345

Doumbia M L 1997 An integrated solution for simulating electrical drive systems with Matlab/Simulink. IEEE International Symposium on Industrial Electronics ISIE'97, Guimaraes, pp. 952-955

Faruque M O, Zhang Y and Dinavahi V 2006 Detailed modeling of CIGRÉ HVDC benchmark system using PSCAD/EMTDC and PSB/SIMULINK. IEEE Trans. Power Delivery 21(1): 378-387

Fuchs E F, Poloujadoff M and Neal G W 1988 Starting performance of saturable three-phase induction motors. IEEE Trans. Energy Conversion 3(3): 624-635

Gamino M, Pedraza J C, Ramos J M and Gorrostieta E 2006 Matlab-C++ interface for a flexible arm manipulator simulation using multi-language techniques. Fifth Mexican International Conference on Artificial Intelligence MICAI '06, pp 369-378

Gerbaud L, Bigeon J and Champenois G 1992 Modular approach to describe electromechanical systemsusing Macsyma to generate global approach simulation software. IEEE 23rd Annual Power Electronics Specialists Conference PESC'92, Toledo, vol. 2, pp. 1189-1196

Gole A M, Keri A, Nwankpa C et al 1997 Guidelines for modeling power electronics in power engineering applications. IEEE Trans. Power Delivery 12(1): 505-514

Henao H, Capolino G A and Martinez-Velasco J A 1997 An approach of CAD for electrical drives using EMTP. Electromotion J. 4(3): 91-100

IEEE Std. 112-1996 1996 IEEE standard test procedure for polyphase induction motors and generators. Electric Machines Committee of the IEEE Power Engineering Society, 58 pages

ITI ${ }^{\circledR}$-SIM 31999 The help manual of ITI ${ }^{\circledR}$-SIM. ITI Gmbh, ITI Gesellschaft für ingenieurtechnische informationsverarbeitung mbH, Gostritzer Strasse 63, D-01217 Dresden, volume I, II et, III

Johansson B, Krus P and Palmberg J-O 2000 Distributed modelling: Object oriented implementation with modelica and transmission lines. Bath Workshop on Power Transmission and Motion Control, PTMC 2000, Bath, England, 13-15 September

Kern A and Hunz U 1993 A modular simulation system for power electronics and control applications. IEEE International Symposium on Industrial Electronics ISIE'93, Budapest, pp. 305-310

Koo K L 2004 Modeling and cosimulation of AC generator excitation and governor systems using simulink interfaced to PSS/E. IEEE Power Systems Conference and Exposition PES'04, vol. 2, pp. 1095-1100, $10-13$

Larsson J, Krus P and Palmberg J-O 2001 Concepts for multi-domain modelling and simulation. The 7th Scandinavian International Conference on Fluid Power SICFP01, Linköping, Sweden, LiTH-IKPCR0254, 30 May-1 June

Larsson J, Johansson B, Krus P and Sethson M 2002 Modelith: A framework enabling tool-independent modelling and simulation. ESS2002, the $14^{\text {th }}$ European Simulation Symposium and Exhibition, Dresden, Germany, 23-26 October

Lechevalier C, Gerbaud L and Bigeon J 1999 Problems in functional analysis of electric drive. International Conference on electrical Machines and Drives IEMD'99, Seattle, pp. 174-176, 9-12 
Levi E 1997 Impact of cross-saturation on accuracy of saturated induction machine models. IEEE Trans. Energy Conversion 12(3): 211-216

Lipo T A and Consoli A 1984 Modeling and simulation of induction motors with saturable reactances. IEEE Trans. Ind. Appl. IA-20(1): 180-189

Li J and Xu L 2001 Investigation of cross-saturation and deep bar effects of induction motors by augmented d-q modelling method. Conference record of the 2001 Industrial Applications Conference 36th IAS Annual Meeting, pp. 745-750

Sakman L E, Guclu R and Yagiz N 2005 Fuzzy logic control of vehicle suspensions with dry friction non-linearity. Sadhana - Acad. Proc. Eng. Sci. 30(4): 649-659

SIMULINK ${ }^{\circledR} 42001$ Dynamic system simulation for MATLAB ${ }^{\circledR}$. Copyright The Mathworks Inc

Smith A C, Healey R C and Williamson S 1996 A transient induction motor model including saturation and deep bar effect. IEEE Trans. Energy Conversion 11(1): 8-15

Schoder K and Feliachi A 2004 Simulation and control of electric shipboard power systems using Modelica and Matlab/Simulink. IEEE Power Engineering Society General Meeting 6(1): 244-248

Wurtz F, Bigeon J, Coulomb J L et al 1998 Methodological guidelines for the use of analytical and numerical models in a design process of an electromagnetic device. IEEE Trans. Magn. 34(4): 34113414 